\title{
Impact of annealing temperature to the performance of hematite-based humidity sensor
}

\author{
W.R.W. Ahmad ${ }^{1}$, M.H. Mamat ${ }^{2}$, Z. Khusaimi ${ }^{3}$, A.S. Ismail ${ }^{4}$, M. Rusop ${ }^{5}$ \\ 1,2,4,5NANO-ElecTronic Centre (NET), Faculty of Electrical Engineering, Universiti Teknologi MARA (UiTM), Malaysia \\ ${ }^{2,3,5}$ NANO-SciTech Centre (NST), Institute of Science (IOS), Universiti Teknologi MARA (UiTM), Malaysia
}

\begin{tabular}{l} 
Article Info \\
\hline Article history: \\
Received Sep 1, 2018 \\
Revised Nov 20, 2018 \\
Accepted Nov 30, 2018 \\
\hline
\end{tabular}

Keywords:

Annealing temperature

Hematite

Humidity sensor

Sensitivity

Sonicated immersion

\begin{abstract}
In the present study, hematite $\left(\alpha-\mathrm{Fe}_{2} \mathrm{O}_{3}\right)$ nanorod structure were grown on fluorine doped tin oxide coated glass substrate via sonicated immersion approach with variation of annealing temperature $\left(350^{\circ} \mathrm{C}-600^{\circ} \mathrm{C}\right)$ in onehour treatment. The impact of varying the temperature of annealing treatment on crystalline phase, structure morphology, optical properties and humidity sensing performance of hematite were examined. X-ray diffraction pattern disclosed a rhombohedral structure with $\alpha$-phase diffraction peaks. The surface morphology images taken from field emission scanning electron microscopy revealed that the hematite nanorod arrays were grown uniformly in all samples and the average diameters of nanorods were measured in the ranges between 55 and $80 \mathrm{~nm}$. Ultraviolet-visible spectroscopy measurement spectra show that all samples exhibited good optical properties. The hematite humidity sensor sample annealed at $400^{\circ} \mathrm{C}$ has demonstrated the highest sensitivity response $(\mathrm{S}=177.78)$ to humidity range between $40 \% \mathrm{RH}$ to 90\% RH.
\end{abstract}

Copyright $(0) 2018$ Institute of Advanced Engineering and Science. All rights reserved.

\section{Corresponding Author:}

Wan Rosmaria Wan Ahmad,

NANO-ElecTronic Centre (NET), Faculty of Electrical Engineering,

Universiti Teknologi MARA (UiTM),

40450 Shah Alam, Selangor, Malaysia.

Email: rosmaria@salam.uitm.edu.my

\section{INTRODUCTION}

Monitoring and controlling the levels of moisture and humidity are considerably vibrant in various environments particularly for industrials, manufacturing, environmental, and medical fields. The demand of ideal humidity sensor with low cost manufacturing as well as high efficiency is essentially crucial. An ultimate humidity sensor should meet special requirements such as high sensitivity, excellent stability and repeatability, and fast response/recovery rate. Various types of humidity sensors such as capacitive [1] and resistive [2]-[6] were studied for different applications. Among these types, resistive humidity sensor is one of the promising sensors for humidity and vapor detection, based on its simplicity of fabrication process, low cost, and relatively high precision of sensor measurement [7]. To fabricate high-efficiency humidity sensors, various materials have been synthesized and explored, which include polymers, ceramics, metal oxide, and their composites. Each material has its own virtue and exact conditions of utilizations.

Metal oxide semiconductors are the most common materials used for electronic sensing devices because of their excellent properties. Metal oxides materials have also been utilized in humidity sensor development. These metal oxides include $\mathrm{TiO}_{2}$ [8], $\mathrm{SnO}_{2}$ [9], and $\mathrm{ZnO}$ [4]. One of the possible metal oxide materials that rarely reported to be applied as humidity sensor is iron oxides (ferric oxides). Iron oxide particularly hematite phase exhibits n-type semiconductor with a wide bandgap of $2.1 \mathrm{eV}$. Early studies of synthesizing iron oxides to be applied as humidity sensors merely focusing on porous ceramic materials with limited characterization results [10]. The effects of different dopant ions to the hematite-based humidity 
sensor behavior have also been investigated [11]. Iron oxide minerals has been existing to be polymorphs, as it can be found in several phases, for instance, hematite $\left(\alpha-\mathrm{Fe}_{2} \mathrm{O}_{3}\right)$, beta-phase iron oxide $\left(\beta-\mathrm{Fe}_{2} \mathrm{O}_{3}\right)$, maghemite $\left(\gamma-\mathrm{Fe}_{2} \mathrm{O}_{3}\right)$, epsilon-phase iron oxide $\left(\varepsilon-\mathrm{Fe}_{2} \mathrm{O}_{3}\right)$ and the mixed oxide, magnetite $\left(\mathrm{Fe}_{3} \mathrm{O}_{4}\right)$. Hematite $\left(\alpha-\mathrm{Fe}_{2} \mathrm{O}_{3}\right)$ is one of the iron oxides that are commonly found in a rock and it is the most durable and environmentally friendly under a broad range of surrounding conditions [12]. Particularly in nanostructures, the highlighted characteristics of hematite were captured in various applications including photoelectrochemical water splitting [13], magnetic devices [14], and lithium ion batteries [15].

Numerous nanostructures of hematite have been synthesized through various synthesis techniques and materials compositions. Synthesis and fabrication process of hematite nanorod array structure development is influenced by different features such as temperature [16], nature of precursors [17], stabilizers, and substrates. Literally, the revolution of enhanced nanostructures contributes unique effects on structural, optical, and electrical performance. Some researchers also added dopants to their solution, for the purposed of enhancing the hematite nanostructure properties [18], [19]. These research works have brought a lot of attention to expand application related to hematite material. Indirectly, all these features excite community attention in developing the applications with variation method preparations. Several approaches to synthesize this material are spin coating deposition, sol-gel method, hydrothermal synthesis, spray pyrolysis, and magnetron sputtering with distinct morphologies and nanostructures. To grow $\alpha-\mathrm{Fe}_{2} \mathrm{O}_{3}$ nanorod arrays, the hydrothermal method is most commonly used, which requires a high-pressure autoclave at high temperature and long deposition time [20], [21].

A proper annealing treatment in post-synthesis process is essential in improving lattice structure and interfacial conductivity between the FTO substrate and the hematite film [16]. Therefore, in this research work, we prepared hematite nanorods samples using sonicated immersion method and annealed at different temperatures. The influences of annealing temperature on the structural, optical, and humidity sensing properties of the synthesized hematite nanorod films were explored. The humidity sensor performance in terms of sensitivity, and stability against the changes of humidity levels were also presented in this work.

\section{RESEARCH METHOD}

Fabrication of hematite nanorod based humidity sensor require a few steps involving substrate preparation, solution mixture, synthesis process, annealing treatment, and characterizations. The $\alpha-\mathrm{Fe}_{2} \mathrm{O}_{3}$ nanorod arrays with nanopores were grown on fluorine tin oxide (FTO) glass substrate in a Schott bottle using low-temperature sonicated sol-gel immersion technique. Generally, FTO glass substrate is transparent, which has a conductive layer (FTO layer) deposited. This conductive layer was used as a surface to grow hematite layer during immersion process. Prior to the synthesis of hematite nanorod array structure, the FTO substrate was cleaned to remove any contaminations. FTO substrates with the dimensions of $2 \times 2 \mathrm{~cm}$ were immersed and cleansed in a beaker filled with methanol $\left(\mathrm{CH}_{3} \mathrm{OH}\right)$. Then, the cleaning process was conducted using sonication process in an ultrasonic cleanser for 10 minutes at $50^{\circ} \mathrm{C}$. The same cleaning procedure was repeated by replacing methanol with deionized (DI) water. After this process, the FTO substrates were dried with nitrogen gas.

Hematite nanorod arrays were synthesized through sonicated sol-gel immersion method. In this procedure, aqueous solution was prepared by dissolving $0.2 \mathrm{M}$ ferric chloride $\left(\mathrm{FeCl}_{3} \cdot 6 \mathrm{H}_{2} \mathrm{O}\right)$, and $0.2 \mathrm{M}$ urea $\left(\mathrm{NH}_{2} \mathrm{CONH}_{2}\right)$ in beaker filled with DI water. The solution was sonicated in ultrasonic water bath at $50^{\circ} \mathrm{C}$ for 30 minutes, and subsequently stirred under room temperature on a stirrer for 5 minutes at $250 \mathrm{rpm}$. Then, the FTO substrates were placed in Schott vial with the conductive surface facing up. The solution mixture was poured gradually into the Schott bottles. Then, the bottles were sealed and immersed into a water bath equipment for two hours at $95^{\circ} \mathrm{C}$. After immersion process, the samples were taken out from the bottles and dried for 10 minutes at $150^{\circ} \mathrm{C}$ in a furnace. Then, the synthesized hematite samples were annealed at different temperatures of $350^{\circ} \mathrm{C}, 400^{\circ} \mathrm{C}, 450^{\circ} \mathrm{C}, 500^{\circ} \mathrm{C}, 550^{\circ} \mathrm{C}$, and $600^{\circ} \mathrm{C}$ for one hour.

The crystallinity properties of the prepared hematite samples were investigated using an X-ray diffraction (XRD; PANalytical X'Pert PRO) with $\mathrm{CuK} \alpha$ radiation. The surface morphologies of the samples were characterized using a field emission scanning electron microscopy (FESEM; JEOL JSM-7600F). The optical properties of the hematite nanorod arrays were determined using an ultraviolet-visible (UV-Vis) spectroscopy (Varian Cary 5000). For the device characterization, the samples were deposited with 60-nmthick Platinum $(\mathrm{Pt})$ metal contact using thermal evaporator. The physical mask was used to create metal contact patterns on the sample during evaporation process. The humidity sensor measurement was performed using a humidity chamber (ESPEC-SH261) equipped with a sensor measurement system (Keithley2400). 


\section{RESULTS AND ANALYSIS}

The XRD patterns of the synthesized samples in Figure 1(a) shows that pure hematite $\left(\alpha-\mathrm{Fe}_{2} \mathrm{O}_{3}\right)$ phased films were grown on the FTO substrates. The other phases of iron oxide such as meghemite and magnetite were not attained in the synthesized samples according to the XRD patterns. The diffraction peaks at $26^{\circ}, 38^{\circ}$, and $53^{\circ}$ with high intensity correspond to FTO layer were also recorded in the XRD patterns due to X-ray penetration into the FTO conductive layer on the glass substrate. The observed peaks for the hematite nanorod arrays are attributed to a polycrystalline structure with rhombohedral lattice system under trigonal crystal system with respect to JCPDS \#33-0664. The samples annealed at high temperatures $\left(500^{\circ} \mathrm{C}\right.$, $550^{\circ} \mathrm{C}$, and $600^{\circ} \mathrm{C}$ ) have five diffraction peaks in the range between $20^{\circ}$ to $90^{\circ}$, which correspond to the main orientations of $\alpha-\mathrm{Fe}_{2} \mathrm{O}_{3}$, namely, (104), (110), (214), (125), and (128) planes. However, the samples annealed at low temperatures $\left(350^{\circ} \mathrm{C}, 400^{\circ} \mathrm{C}\right.$, and $\left.450^{\circ} \mathrm{C}\right)$ show non-appearance of the diffraction peak corresponds to (110) plane orientation as indicated in Figure 1(b). This condition is due to a nature of low-annealingtemperature process, which has insufficient heat energy for a complete crystallization process.

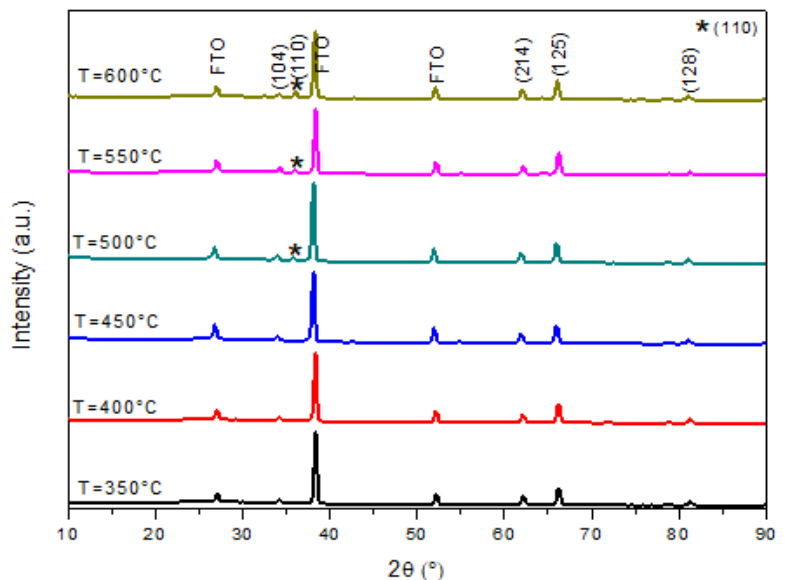

(a)

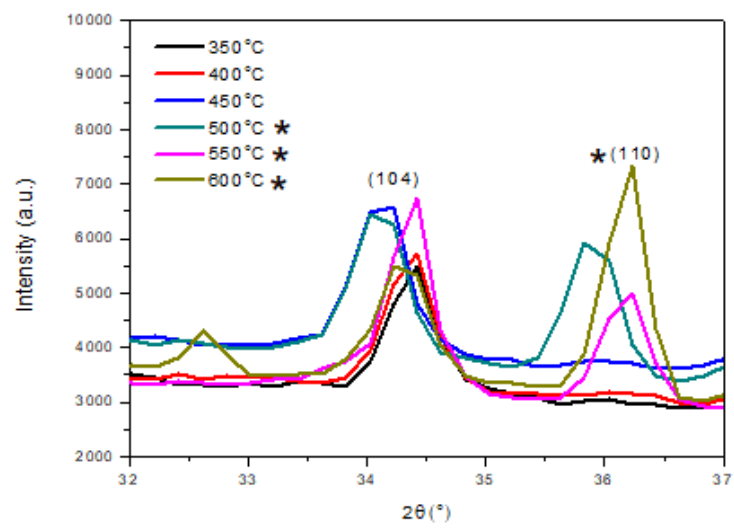

(b)

Figure 1. (a) The XRD patterns of hematite nanorod arrays at different annealing temperature. (b) The diffraction peaks in the range between $22^{0}-27^{0}$ showing the appearance of (110) plane orientation peak for samples annealed at $500^{\circ} \mathrm{C}, 550^{\circ} \mathrm{C}$, and $600^{\circ} \mathrm{C}$
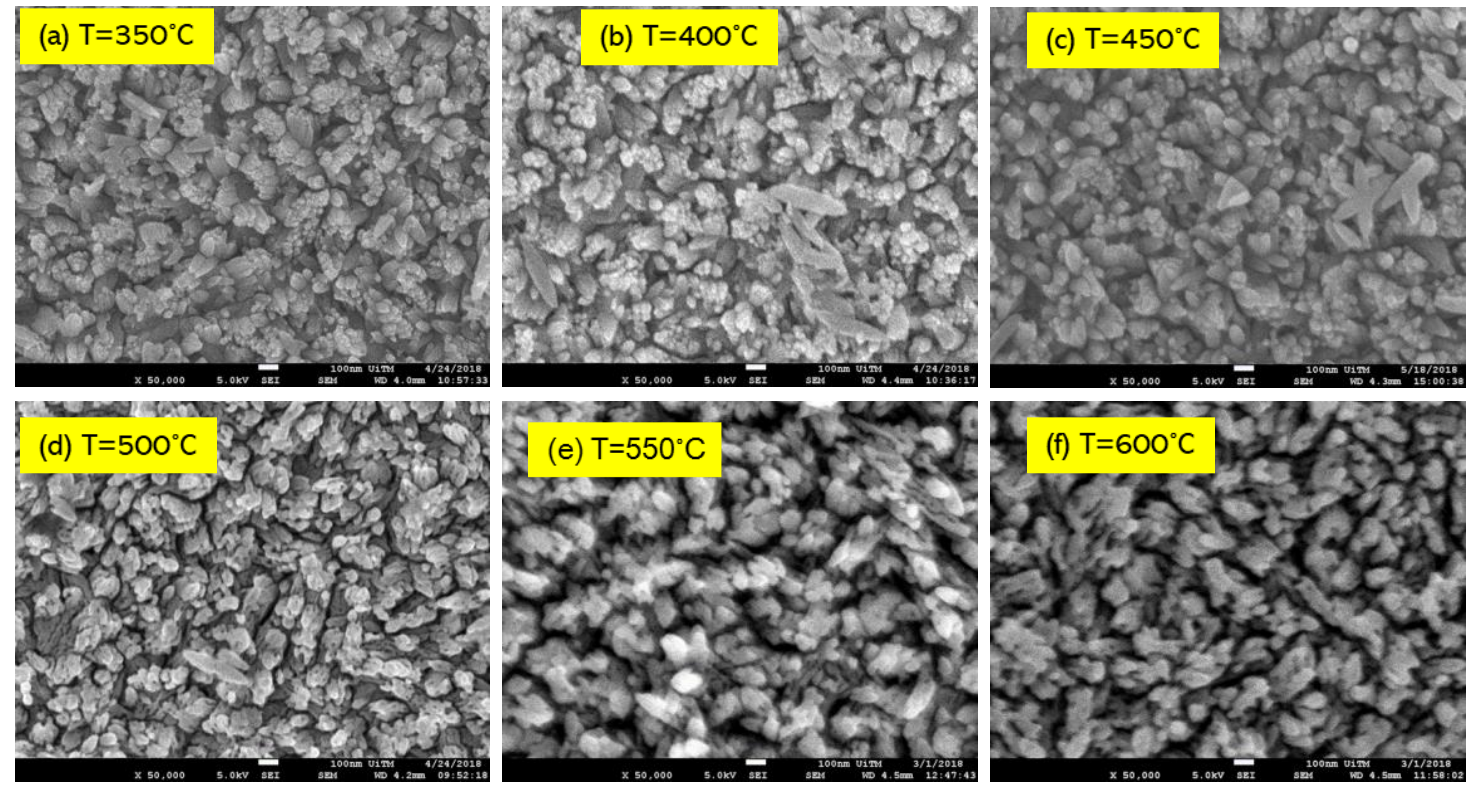

Figure 2. FESEM images of $\alpha-\mathrm{Fe}_{2} \mathrm{O}_{3}$ nanorod arrays at different annealing temperature of (a) $350^{\circ} \mathrm{C}$, (b) $400^{\circ} \mathrm{C}$, (c) $450^{\circ} \mathrm{C}$, (d) $500^{\circ} \mathrm{C}$, (e) $550^{\circ} \mathrm{C}$, and (f) $600^{\circ} \mathrm{C}$ at $50,000 \times$ magnification 
The FESEM images in Figure 2 depict the surface morphologies of the prepared hematite nanorod array samples at different annealing temperatures taken at 50,000× magnification. From the surface morphology images, all samples exhibit nanorod structures, which grown perpendicular to the substrates. For the samples annealed at temperature higher than $500^{\circ} \mathrm{C}$, large pore areas are observed between the nanorods. These samples also exhibit high porous structures. The formation of pore areas between the nanorods might be due to the evaporation of impurities during the annealing treatment and the merging activity of the nanorods at high temperature. The average diameters of hematite nanorod annealed at different temperatures are listed in the Table 1 . The table shows that the average diameter sizes of hematite nanorods are ranging from $50 \mathrm{~nm}$ to $80 \mathrm{~nm}$.

The optical properties of hematite nanorod samples at different annealing temperature were determined from the UV-vis transmittance spectra in the range of 300-800 nm, as indicated in Figure 3(a). It is observed that all samples exhibit high transmission greater than $80 \%$ in the wavelength regions between 600 to $800 \mathrm{~nm}$. The spectra reveal that the samples annealed at lower temperature have higher transmittance properties. It also can be perceived that the sample annealed at $550^{\circ} \mathrm{C}$ has the lowest transmittance values. The high transmittance properties might be attributed to the smaller nanostructure size which leads to higher porosity in the hematite nanorods films. Thus, it reduces the optical scattering effect and enhances the transmission of the lights through the sample. From the transmittance spectra, the absorption coefficients of thin films were calculated using Lambert's law as shown in (1):

$$
\alpha=\frac{1}{t} \ln \left(\frac{1}{T}\right)
$$

where $t$ is the nanostructure's film thickness which was estimated from cross-sectional images and $\mathrm{T}$ is the measured transmittance. Figure 3(b) depicts the absorption coefficient spectra of the hematite films. From the absorption coefficient spectra, the hematite nanorod sample annealed at high temperature exhibits high UV absorption properties at wavelengths below $600 \mathrm{~nm}$.

Figure 4 shows Tauc's plot of the hematite nanorod arrays derived using (2). The equation for optical band gap energy estimation is shown (2):

$$
(a h v)^{2}=A\left(h v-E_{g}\right)
$$

Here, $\alpha$, hv, A, and $\mathrm{E}_{\mathrm{g}}$ represent the absorption coefficient, photon energy, constant, and band gap energy, respectively. The band gap energy of the hematite nanorod arrays were determined from the extrapolation of the linear side of the graph. The estimated optical band gap values of the samples are in the ranges between $2.1 \mathrm{eV}$ to $2.2 \mathrm{eV}$, which consistent with the reported values in literature [22].

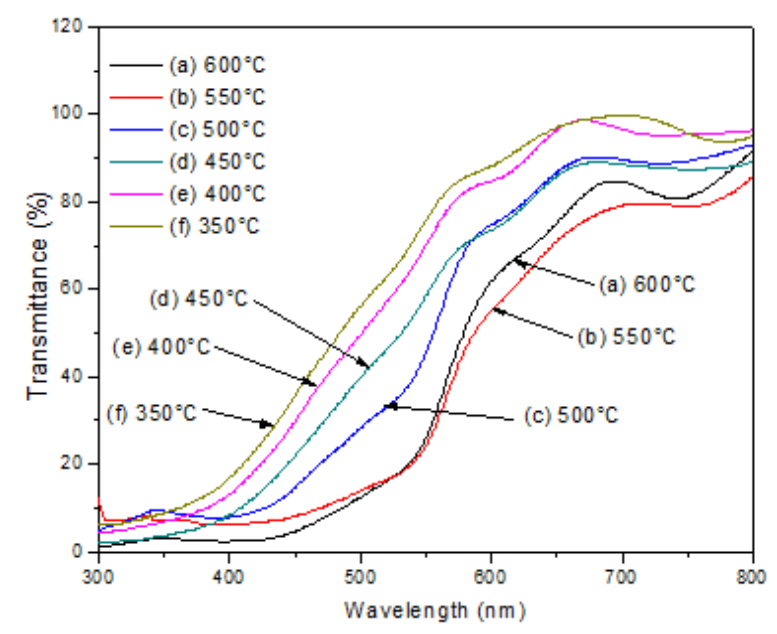

(a)

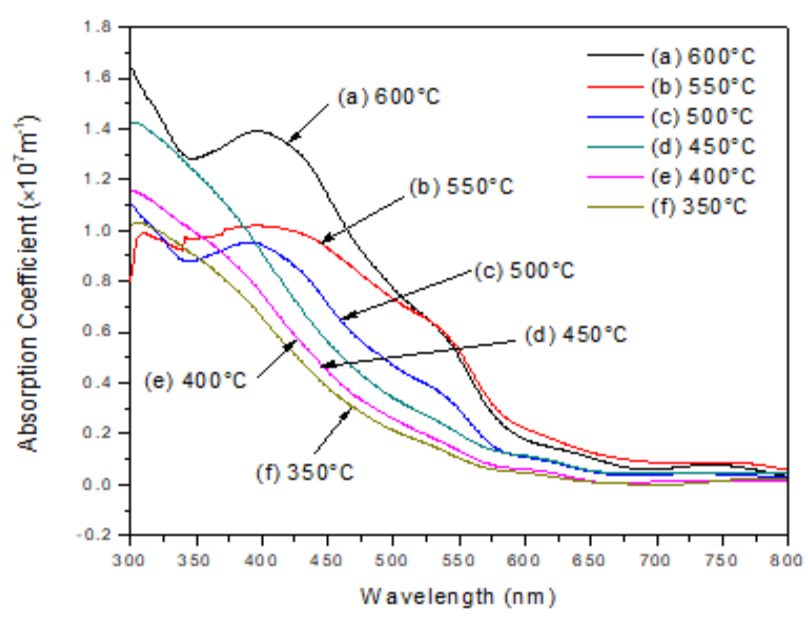

(b)

Figure 3. Optical properties of hematite nanorod array film samples at different annealing temperatures: (a) transmittance and (b) absorption coefficient spectra 


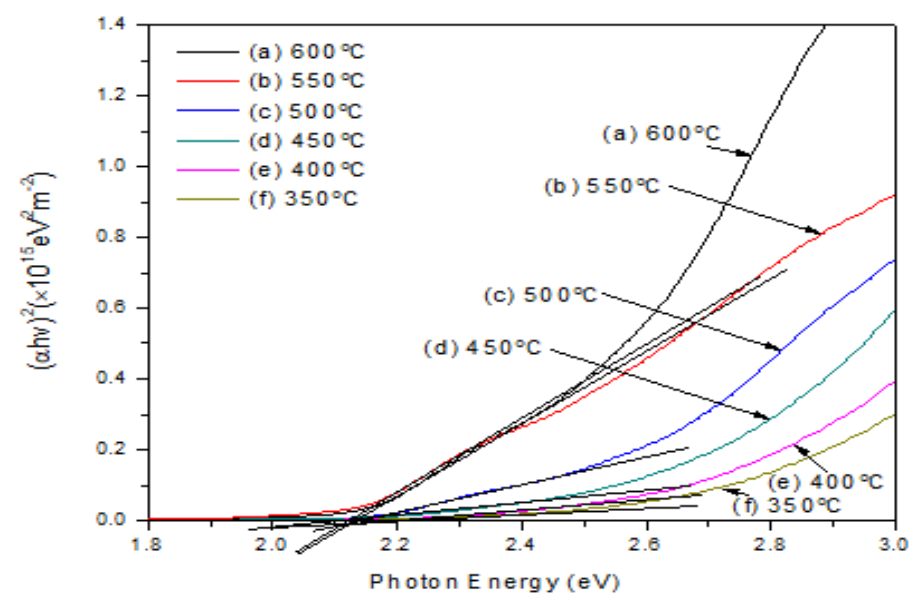

Figure 4. Estimation of the optical band gap energy $\left(\mathrm{E}_{\mathrm{g}}\right)$ using Tauc's plot

Table 1. Average diameter and humidity sensing sensitivity of hematite nanorod arrays prepared at different annealing temperatures

\begin{tabular}{ccc}
\hline Annealing Temperature & Average Diameter $(\mathrm{nm})$ & Sensitivity $(40-90) \% \mathrm{RH}$ \\
\hline $350^{\circ} \mathrm{C}$ & 55 & 22.41 \\
$400^{\circ} \mathrm{C}$ & 80 & 177.78 \\
$450^{\circ} \mathrm{C}$ & 76 & 39.40 \\
$500^{\circ} \mathrm{C}$ & 62 & 119.33 \\
$550^{\circ} \mathrm{C}$ & 66 & 29.77 \\
$600^{\circ} \mathrm{C}$ & 64 & 5.51 \\
\hline
\end{tabular}

The performance of the fabricated hematite humidity sensors was measured through the variation of humidity conditions. The absorption process (response) was measured for relative humidity ranges from $40 \%$ to $90 \% \mathrm{RH}$, while the desorption process (recovery) was measure in the ranges between $90 \%$ to $40 \% \mathrm{RH}$. The humidity response and recovery route were measured in humidity chamber with $5 \mathrm{~V}$ bias at room temperature $\left(25^{\circ} \mathrm{C}\right)$. It can be understood from the plotted graph in Figure 5(a) that all samples exhibit a good humidity response with rapid changes of current signal as the humidity level increases from $40 \% \mathrm{RH}$ to $90 \% \mathrm{RH}$, and promptly decays as the humidity level is ramped down from $90 \% \mathrm{RH}$ to $40 \% \mathrm{RH}$. The sensitivity, S, of the sensor was estimated using the following (3):

$$
S=\frac{R_{a}}{R_{r h}}
$$

where $R_{a}$ and $R_{r h}$ is the resistance of the sensor exposed to the initial humidity level (40\%RH) and maximum humidity level $(90 \% \mathrm{RH})$, respectively. The resistance values were attained from the current values of the response curves using Ohm's law (V=IR). Table 1 presents the sensitivity, $\mathrm{S}$ calculated for all samples. It can be perceived that the sample annealed at $400^{\circ} \mathrm{C}$ has the highest sensitivity value of 177.78 , follows by sample annealed at $500^{\circ} \mathrm{C}$ with $\mathrm{S}=119.33$. The sample annealed at $600^{\circ} \mathrm{C}$ is found to be the least sensitive to humidity with sensitivity value of 5.51 . The high sensitivity value obtained for these samples is mainly attributed to nanopores, which formed between $\alpha-\mathrm{Fe}_{2} \mathrm{O}_{3}$ aggregates and facilitate high surface area for water molecules to diffuse across the sample.

The humidity sensor measurement (respond and recovery) were repeated for a few cycles to measure the stability of the sensor detection. Figure 5(b) illustrates the repeatability current response to different humidity level for sample annealed at $400^{\circ} \mathrm{C}$. The sensor measurement results demonstrate a good stability response, with almost identical curves observed over five cycles. Figure 5(c) illustrates the current responses of sample annealed at $400^{\circ} \mathrm{C}$ to different humidity levels. The plot shows that the sample response well with the different humidity levels. Figure 5(d) shows the sensitivity values of the samples at different humidity levels. The graph reveals that the sample annealed at $400^{\circ} \mathrm{C}$ exhibits the highest sensitivity values at various humidity levels. 


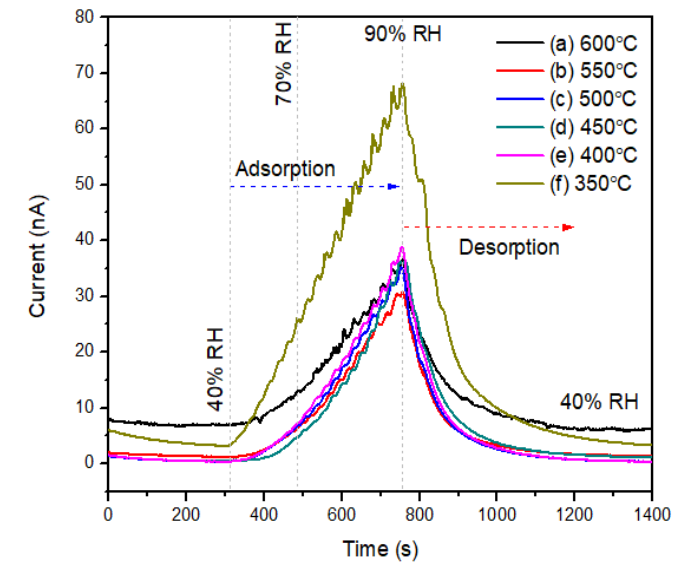

(a)

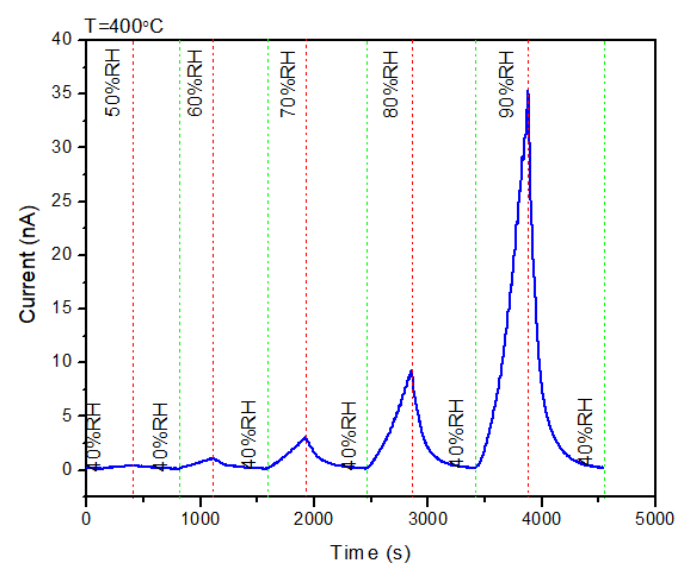

(c)

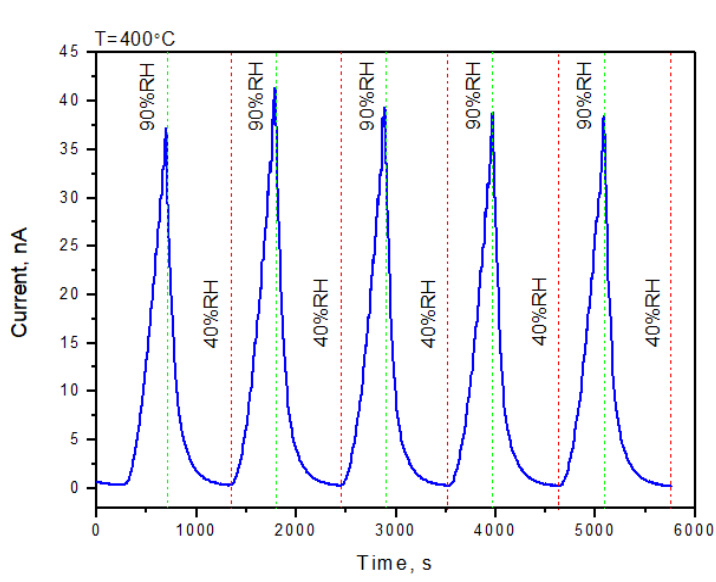

(b)

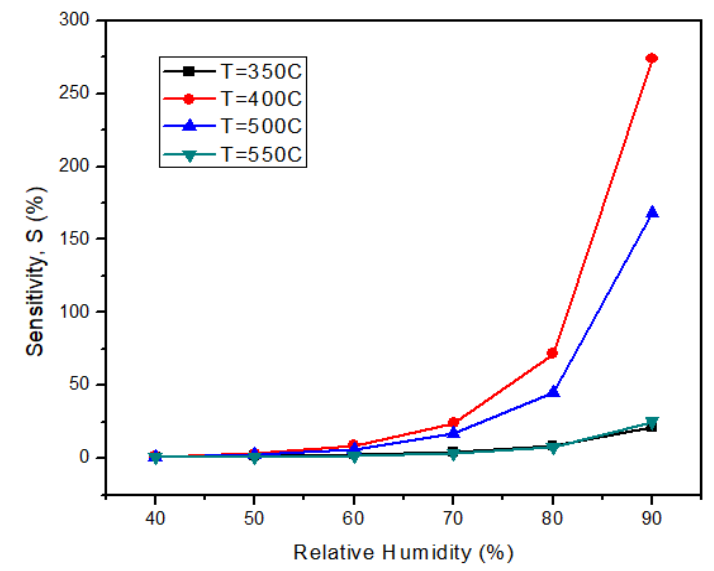

(d)

Figure 5. (a) Humidity sensor responses of hematite nanorod array-based humidity sensors at different annealing temperatures. (b) Repeatability humidity response of fabricated hematite humidity sensor annealed at $400^{\circ} \mathrm{C}$, (c) Current responses of sample $400^{\circ} \mathrm{C}$ to different humidity (d) Sensitivity plot of samples at different humidity levels

The generated current at high humidity level can be explained by the fact that the electrolytic conductions occur in the sample. High density of water molecules at high humidity level promotes proton hopping inside the films, which occurs along a series of hydrogen bonds between hydronium ions and water molecules. When the surface area of hematite nanorod increases, the rate of water adsorption on the surface improves at the increased humidity level. Consequently, the electrical properties of the devices change and eventually cause the electrolytic conduction in the films. The hematite nanorod arrays have high surface area due to the nanorod structure itself and the formation of nanopores on the nanorod surface. Thus, it can be expected that the water adsorption under various humidity level of hematite nanorod arrays are better than that of the conventional nanostructures such as nanoparticles and nanocubes.

\section{CONCLUSION}

Hematite $\left(\alpha-\mathrm{Fe}_{2} \mathrm{O}_{3}\right)$ nanorod arrays were successfully prepared via sonicated immersion method on FTO coated glass substrates at different annealing temperatures ranging from $350^{\circ} \mathrm{C}$ to $600^{\circ} \mathrm{C}$. The XRD pattern revealed that $\alpha-\mathrm{Fe}_{2} \mathrm{O}_{3}$ exhibits a rhombohedral structure with five diffraction peaks correspond to (104), (110), (214), (125), and (128) plane orientations. Diffraction peak correspond to (110) plane orientation appears for samples annealed at $500^{\circ} \mathrm{C}$ and above. Hematite nanorod samples exhibits a uniform growth and small diameter size ranging from $55 \mathrm{~nm}$ to $80 \mathrm{~nm}$. The optical band gap of hematite annealed at different temperatures ranges from $2.1 \mathrm{eV}$ to $2.2 \mathrm{eV}$. The highest sensitivity was recorded for the sample annealed at $400^{\circ} \mathrm{C}$ with the value of 177.78 when the humidity changes from $40 \% \mathrm{RH}$ to $90 \% \mathrm{RH}$. 
The humidity response for hematite nanorod array-based sensors also exhibit a good repeatability and stability over five cycles.

\section{ACKNOWLEDGEMENTS}

This work was supported by REI grant (600-IRMI/REI 5/3 (017/2018)). The authors would like to acknowledge the Institute of Research Management and Innovation (IRMI) and Faculty of Electrical Engineering of UiTM for their support of this research.

\section{REFERENCES}

[1] A. Tripathy, S. Pramanik, A. Manna, S. Bhuyan, N. F. Azrin Shah, Z. Radzi, and N. A. Abu Osman,"Sign and Development for Capacitive Humidity Sensor Applications of Lead-Free Ca, Mg, Fe, Ti-Oxides-Based ElectroCeramics with Improved Sensing Properties via Physisorption," Sensors, vol. 16, pp. 1135, 2016.

[2] I. Rahim, M. Shah, A. Khan, A. Zhong, M. Li, R. Ahmed, H. Li, Q. Wei, Y. Fu, M. Shah, A. Khan, A. Zhong, M. Li, R. Ahmed, H. Li, Q. Wei, and Y. Fu, "Capacitive and resistive response of humidity sensors based on graphene decorated by PMMA and silver nanoparticles," Sensors and Actuators B: Chemical, vol. 267, pp. 42-50, 2018.

[3] B. Yadav, A. K. Srivastava, and P. Sharma, "Resistance Based Humidity Sensing Properties of TiO2," Sensors \& Transducers Journal, vol. 81, pp. 1348-1353, 2007.

[4] A. S. Ismail, M. H. Mamat, N. D. Md. Sin, M. F. Malek, A. S. Zoolfakar, A. B. Suriani, A. Mohamed, M. K. Ahmad, and M. Rusop, "Fabrication of Hierarchical Sn-doped ZnO Nanorod Arrays Through Sonicated Sol-Gel Immersion for Room Temperature, Resistive-Type Humidity Sensor Applications," Ceramic International, vol. 42, pp. 9785-9795, 2016.

[5] J. M. Tulliani and P. Bonville, "Influence of the Dopants on the Electrical Resistance of Hematite-Based Humidity Sensors," Ceramic International, vol. 31, pp. 507-514, 2005.

[6] K. J. Park and M. S. Gong, "A Water Durable Resistive Humidity Sensor Based on Rigid Sulfonated Polybenzimidazole and Their Properties," Sensors and Actuators B: Chemical, vol. 246, pp. 53-60, 2017.

[7] Z. Chen and C. Lu, "Humidity Sensors: A Review of Materials and Mechanisms," Sensor Letters, vol. 3, pp. 274-295, 2005.

[8] P.-G. Su and L.-N. Huang, "Humidity Sensors Based on Tioz Nanoparticles/Polypyrrole Composite Thin Films," Sensors and Actuators B: Chemical, vol. 123, pp. 501-507, 2007.

[9] M. Parthibavarman, V. Hariharan, and C. Sekar, "High-sensitivity Humidity Sensor Based on Sno2 Nanoparticles Synthesized by Microwave Irradiation Method," Materials Science and Engineering: C, vol. 31, (5), pp. 840-844, 2011.

[10] G. Neri, a. Bonavita, S. Galvagno, N. Donato, and a. Caddemi, "Electrical Characterization of $\mathrm{Fe}_{20} \mathrm{O}_{3}$ Humidity Sensors Doped with $\mathrm{Li}^{+}, \mathrm{Zn}^{2+}$ and $\mathrm{Au}^{3+}$ Ions, "Sensors and Actuators B: Chemical, vol. 111-112, pp. 71-77, 2005.

[11] Z. Cao, M. Qin, Y. Gu, B. Jia, P. Chen, and X. Qu, "Synthesis and Characterization of Sn-Doped Hematite as Visible Light Photocatalyst," Materials Research Bulletin, vol. 77, pp. 41-47, 2016.

[12] C. Wu, P. Yin, X. Zhu, C. OuYang, and Y. Xie, "Synthesis of Hematite (Alpha- $\mathrm{Fe}_{2} \mathrm{O}_{3}$ ) Nanorods: Diameter-Size and Shape Effects on Their Applications in Magnetism, Lithium Ion Battery, and Gas Sensors, The Journal of Physical Chemistry B, vol. 110, pp. 17806-12, 2006.

[13] A. Subramanian, E. Gracia-Espino, A. Annamalai, H. H. Lee, S. Y. Lee, S. H. Choi, and J. S. Jang, "Effect of Tetravalent Dopants on Hematite Nanostructure for Enhanced Photoelectrochemical Water Splitting, " Applied Surface Science, vol. 427, pp. 1203-1212, 2018.

[14] A. Lassoued, M. S. Lassoued, B. Dkhil, S. Ammar, and A. Gadri, "Synthesis, Structural, Morphological, Optical And Magnetic Characterization of Iron Oxide (A-Fe $\left.{ }_{2} \mathrm{O}_{3}\right)$ Nanoparticles by Precipitation Method: Effect of Varying the Nature of Precursor, " Physica E: Low-dimensional Systems and Nanostructures, vol. 97, pp. 328-334, 2018.

[15] M. Balogun, Z. Wu, Y. Luo, W. Qiu, X. Fan, B. Long, M. Huang, P. Liu, and Y. Tong, "High Power Density Nitridated Hematite (A- $\mathrm{Fe}_{2} \mathrm{O} 3$ ) Nanorods as Anode for High-Performance Flexible Lithium Ion Batteries, " Journal of Power Sources, vol. 308, pp. 7-17, 2016.

[16] Y. W. Phuan, M. N. Chong, T. Zhu, S. T. Yong, and E. S. Chan, "Effects of Annealing Temperature on the Physicochemical, Optical and Photoelectrochemical Properties of Nanostructured Hematite Thin Films Prepared Via Electrodeposition Method, " Materials Research Bulletin, vol. 69, pp. 71-77, 2015.

[17] A. Lassoued, M. S. Lassoued, B. Dkhil, S. Ammar, and A. Gadri, "Synthesis, Structural, Morphological, Optical and Magnetic Characterization of Iron Oxide (A- $\left.\mathrm{Fe}_{2} \mathrm{O}_{3}\right)$ Nanoparticles by Precipitation Method: Effect of Varying the Nature of Precursor, Physica E: Low-dimensional Systems and Nanostructures, vol. 97, pp. 328-334, 2018.

[18] K. Bindu, K. M. Ajith, and H. S. Nagaraja, "Electrical, Dielectric and Magnetic Properties of Sn-Doped Hematite (A-Sn $\left.\mathrm{fe}_{2}-\mathrm{xO}_{3}\right)$ Nanoplates Synthesized by Microwave-Assisted Method," Journal of Alloys and Compounds, vol. 735 , pp. 847-854, 2018.

[19] J. Lin, X. Zhang, L. Zhou, S. Li, and G. Qin, "Pt-doped $\alpha-\mathrm{Fe}_{2} \mathrm{O}_{3}$ Photoanodes Prepared by A Magnetron Sputtering Method for Photoelectrochemical Water Splitting," Materials Research Bulletin, vol. 91, pp. 214-219, 2017.

[20] L. Li, C. Liu, Y. Qiu, N. Mitsuzak, and Z. Chen, "The Influence of the Hydrothermal Temperature and Time on Morphology and Photoelectrochemical Response of A- Fe203 Photoanode," Journal of Alloys and Compounds, vol. 696, pp. 980-987, 2017. 
[21] C. Colombo, G. Palumbo, E. Di Iorio, X. Song, Z. Jiang, Q. Liu, and R. Angelico, "Influence of Hydrothermal Synthesis Conditions on Size, Morphology and Colloidal Properties of Hematite Nanoparticles," Nano-Structures and Nano-Objects, vol. 2, pp. 19-27, 2015.

[22] Q. Meng, Z. Wang, X. Chai, Z. Weng, R. Ding, and L. Dong, "Fabrication of Hematite (A- $\left.\mathrm{Fe}_{2} \mathrm{O}_{3}\right)$ Nanoparticles Using Electrochemical Deposition," Applied Surface Science, vol. 368, pp. 303-308, 2016.

\section{BIOGRAPHIES OF AUTHORS}

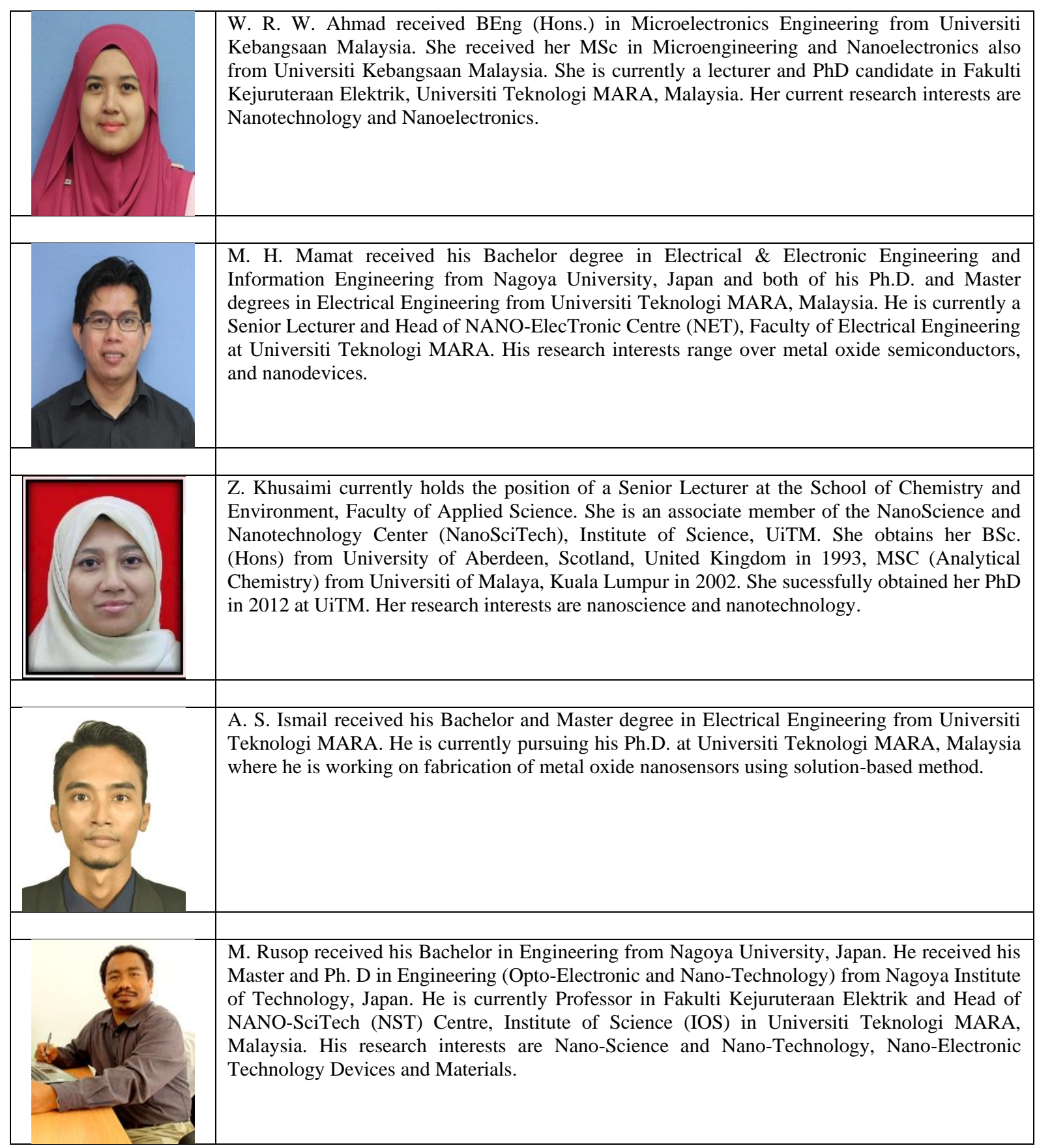

